\title{
Natural Resource Rental Income and R\&D Intensity
}

\author{
William R. DiPietro \\ Professor of Economics. Daemen College
}

\begin{abstract}
The ease of obtaining rental income for countries with abundant natural resources having substantial world demand may lead to a diminution in the pursuit of other forms of income such as income obtained from investing in research and development. If this proves to be the case, then it can have profound negative consequences for economic growth. In this light, this paper employs cross country regression analysis to test to see whether a greater share of natural resource rental income in national income is unfavorable for country R\&D Intensity. Analyzing data for $\mathbf{2 0 1 0}$ for a fairly substantial set of countries, the findings of the paper lend credence to the hypothesis that $R \& D$ intensity is negatively related to the size of the share of natural resource rental income relative to total income. This suggests that countries endowed with natural resources that generate high levels of rental income must be very diligent in order to avoid the potential negative ramifications of rental income on their economic development.
\end{abstract}

Research and development is the key to economic development and to economic growth. Investment in R\&D leads to new ideas, new products, and better processes, causing lower costs by reinventing and revolutionizing production. Given R\&D is so crucial to the improvement of economic well-being, indentifying and understating the determinants of R\&D is of fundamental importance. This paper focuses on one possible driver, a potential negative driver, of R\&D intensity, natural resource rental income.

The Classical economists were very concerned with the potential negative effect of rental income on economic development with the passage of time. They saw profits as essential to economic growth and predicted, that, with the maturing of an economy, the share of rental income to total economic income would increase at the expense of profit's share, thereby reducing investment, and eventually leading to a steady, no growth state.

Looking at the nations of the world, a lot of the nations that are rich with natural resources, such as oil, are not necessarily the countries with the highest growth and most rapid economic development. Historically, during the peak period of the Spanish empire, when enormous amounts of gold were flowing into Spain from the New Word, industrialization in Spain did not proceed at a brisk pace, but, rather, it lagged far behind that of England.

On a theoretical basis, one can look at rental income and income from research and development as two totally different alternative ways of obtaining income, each with its own particular characteristics, and each with its own culture and associated set of values. R\& D is a very risky proposition, undertaken by people who are actively willing to take risks. While rental income, on the other hand, is very passive, and, under the right conditions, may not be very risky at all. Favored owners of a resource in fixed supply, the demand for which is projected to go higher and higher with the passage of time, can just comfortably sit back while the rents flow in. In terms of culture and values, rents from oil and other sources may act as a 
barrier or impediment to economic development. They can foster a culture of oil entitlement in the society as a whole and class superiority among rental receiving elites, with little need or desire to acquire income in any other way, general contempt for people who earn money in any other way, and little longing to gain money from investing in R\&D and productive activities. A good analogy is the antebellum South of the U.S. in which it was considered, not just socially undesirable, but degrading, to work with one's hands.

The investigation of the relationship between $R \& D$ intensity and natural resource rental income share in the paper is broken down into five sections. To provide some contextual background and moorings for the reader, the first section provides a brief literature review of some of the recent research looking at the determinants of research and development. The second section develops and discusses a small formal model of research intensity highlighting on the share of natural resource rental income to total income. The third section describes the sources of the variables that are used in the empirical analysis. The fourth shows the results of cross country regressions of $R \& D$ intensity on the share of natural resource rental income to total income and on other variables. The fifth and last section concludes.

\section{QUICK LITERATURE REVIEW}

Using regression analysis on a pooled sample of eighty eight countries from the 1980's and the 1990 's, Bebczuk looks at a fairly large set of potential explanatory variables for R\&D expenditures (Bebczuk 2002). His explanatory variables include the investment rate, the rule of law, tertiary school enrollment, the level of financial development, trade openness, percentage of manufacturing exports to total exports, incoming foreign direct investment, economic growth, and the standard deviation of economic growth. He finds that R\&D expenditures as a percentage of GDP are positively related to the rule of law, tertiary school enrollment, credit to private sector, the share of manufacturing exports to total exports, and incoming foreign direct investment, and are negatively related to trade openness and the rate of investment.

Kanwar and Evenson focus on the extent of intellectual property rights protection as a critical determinant of the share of R\&D expenditures to GDP (Kanwar and Evenson 2003). Controlling for human capital, savings to GDP (as a proxy of the availability of external funding for R\&D), political instability, and other variables, they employ generalized least squares with random effects on a sample consisting of thirty two countries using five year averages for the two periods from 1981 through 1990. They find that individual property protection has a consistent positive and significant effect on R\&D expenditures to GDP. Their results also suggest that the share of savings to GDP and human capital are relevant for the rate of research and development.

Wang believes that institutional quality is essential for innovation (Wang 2013). He hypothesizes that improved institutional quality leads to greater R\&D intensity. Using both the proportion of scientists and engineers to the total labor force and the proportion of R\&D expenditures to GDP as different measures of R\&D intensity, he regresses R\&D intensity on four alternative indices of institutional quality while controlling for latitude, the percentage of Catholics and Muslims to the population, whether or not a country is landlocked, and whether or not a country has a French legal origin. His results support the contention that institutional quality has a positive impact on $R \& D$ intensity. Regardless of which measure he uses for $R \& D$ intensity, regardless of whether he employs ordinary least squares or two stage least squares with a variety of different instruments, and regardless of which index he utilizes to proxy institutional quality, he finds that institutional quality is a positive and highly significant. By splitting his sample on the basis of various characteristics, he also investigates characteristics that may be important for the size of the coefficient on institutional quality. These 
undertakings suggest that the impact of institutional quality on R\&D intensity is higher in financially more developed countries, is not sensitive to the degree of trade openness,and is greater in countries with more human capital.

Instead of considering, as most researchers, the determinants of total country R\&D intensity, Falk empirically investigates the potential sources of business R\&D intensity, the percentage of business R\&D to GDP (Falk 2006). Using five year averages on panel data for OECD counties for the period 1970 to 2002, he considers a whole set of factors for business R\&D intensity. They include variables for patent protection, government subsidies for business R\&D, openness, government tax incentives for Business $R \& D$, industrial structure, human capital, and others. Although the results on the relevance for business R\&D intensity for many of his determinants differ depending on whether he uses a static fixed effect estimator, a dynamic system GMM estimator, or a first-differenced GMM estimator, he consistently finds that both fiscal tax incentives and the percentage of university R\&D spending to GDP have positive and significant effects on business R\&D intensity.

Those who favor the adoption of an export growth model for economic development will be pleased to hear that exports may be conducive for R\&D. Yang and Chen, looking at Indonesian plant level data for the period 1998 to 2000, find evidence that, plant exporting is positively related to plant research and development (Yang and Chen 2012).

A country's corporate governance may be important for R\&D. Looking at 1287 companies in eleven countries over the fourteen year period from 1990 to 2003, and controlling for other firm level R\&D determinants such as long term debt and dividends, Hillier and his co-authors, employing a systems GMM estimator on an unbalanced panel, find that firm R\&D depends on cash flow, and that the sensitivity of firm R\&D to firm cash flow lessens with better countrylevel corporate governance (Hillier et al 2011).

Categorizing the studies into four broad groups, Becker provides an extensive survey of the recent literature on the empirical research on the drivers of R\&D investment (Becker 2013). Given that some of the studies indicate that there may exist non-linearities such as a inverted $U$ shaped relationship between R\&D and competition, she recommends future investigation looking at the possibility of non-linear relationships between $R \& D$ and its various determinants. From her review of the typical empirical studies employing linear specifications, she summarily concludes, in general, that public subsidies and tax credits, internal finance, availability of human capital, and proximity to universities are favorable to private R\&D, but that foreign $R \& D$ appears to crowd out domestic $R \& D$.

\section{THE THEORETICAL MODEL}

The theoretical model consists of a single equation with an associated partial derivative. The equation, with its accompanying partial derivative, is as follows.

1. $\mathrm{I}=\mathrm{g}(\mathrm{R}, \mathrm{C}) \delta \mathrm{I} / \delta \mathrm{R}<0$

In the equation, I represents $R \& D$ intensity, the percentage of $R \& D$ to GDP, $R$ is natural resource rental share in the economy, the percentage of natural resource rents to GDP, and C represents a set of control variables. In words, the equation with its partial derivative simply hypothesizes that the intensity of country research and development intensity is negatively related to the share of natural resource rental income when adjusting for control variables.

The primary theoretical reason behind the proposed negative relationship between $R \& D$ intensity and natural resource rental income share is that rental income is considered to be a 
substitute way for procuring income to other means of obtaining income such as investment in R\&D. That is to say, it is argued that greater income from natural resource rental income, or greater availability of rental natural resource rental income, leads to lessened pursuit of trying to acquire income from other sources. An easier less risky way of gaining income, with an appealing life style, replaces a harder riskier way.

A secondary channel by which high natural resource rental incomes are likely to negatively influence R\&D is through their impact on the industrial structure working through their effect on the exchange rates. Higher rental resource countries are likely to have higher exchange rates, exchange rates above what they would otherwise be. These higher exchange rates discourage exports, and the development of manufacturing and industrial sector which is a highly R\&D intensive sector.

In addition to the main variable of interest, rental income from natural resources, four control variables will be considered. The first is the level of economic development. To practically no one's surprise, research and development intensity is anticipated to be positively related to the level of economic development. More developed countries have greater incomes and resources to devote to all activities. Compared to lesser developed countries, they can not only readily pore resources directly into $\mathrm{R} \& \mathrm{D}$, but also into education, and into the improvement of educational quality, both of which are so important for the production of technicians and scientists that are indispensable for the undertaking of research and development. In addition, more developed countries are going to have economic structures that are more favorable for R\&D investment. They will already have large numbers of scientists, and a greater quantity of pre-existing and on-going R\&D institutions.

The second control variable is the size of the government. While not at all for certain, and for particular countries it may not be the case, in general, the size of government is likely to be a positive force for country R\&D. The government, if effective, creates an overall environment conducive to R\&D. It establishes law and order and internal security. It builds and maintains an educational system that produces the scientists, engineers, and technicians that are essential for $R \& D$. It can make available funding for $R \& D$, and can provide incentives for $R \& D$ through subsidies. In addition, the government itself engages in R\&D, especially in all important basic R\&D. Investment in basic R\&D, in a lot of cases, is not profitable and, therefore would not be undertaken by the private sector, but basic R\&D is replete with positive spillovers that generate opportunities for investment in private R\&D.

The third control variable is the ability to finance risky projects. R\&D is a particularly risky investment, and risky investments can be difficult to finance. Naturally, it is predicted that the easier it is to obtain finance for risky ventures, the greater will be the level of investment in risky ventures such as $R \& D$. Thus, $R \& D$ intensity is expected to be positively related to the ease with which risky activities can be financed.

Finally, the last control variable to be considered is globalization. As some other studies have found, to their surprise, that increased globalization (greater trade) lowers R\&D intensity, a negative relationship between $R \& D$ intensity and globalization is also predicted here. While some may argue theoretically that greater trade enhances competition leading to the need for greater R\&D to stay competitive, from the Schumpeterian point of view, the increased competition from globalization reduces protected monopolistic profits that are necessary to undertake R\&D, thereby lessening R\&D investment. Furthermore, because of the absence or lack of global uniformity in intellectual property protection across countries, that increased trade (globalization) makes R\&D more risky leading to lower rate of R\&D investment. 
In sum, R\&D intensity is theoretically anticipated to be negatively related to the share of rental income to GDP and to globalization, but to be positively related to the level of economic development, the size of the government, and the ease of obtaining finance.

\section{VARIABLE SOURCES}

The measure of country R\&D intensity is the percentage of R\&D to GDP for 2010. The share of natural resource rental income is the percentage of natural resource rental income to GDP for 2010.The level of economic Development is captured by employing GDP per capita for 2010. Government size is quantified by utilizing the percentage of government expenditures to GDP for 2010. Globalization, or the extent of trade, is measured by the percentage of total trade (exports plus imports) to GDP for 2010. the source for every one of these variables is the World Bank (World Bank 2014).

Lastly, the variable for measuring the ease of obtaining finance for risky ventures is taken from the World Economic Forum's Global Competitiveness Report for 2010-2011 (World Economic Forum 2011). It is their Venture Capital Availability index from 2009 to 2010. The index ranges from a low value of one (very difficult to find capital) to a high value of seven (very easy to obtain capital). The index is constructed on the basis of answers to the survey question, "In your country, how easy is it for entrepreneurs with innovative but risky projects to find venture capital?".

\section{EMPIRICAL RESULTS}

Table I shows the results of cross country regressions of R\&D intensity on natural resource rental income share and the four control variables.

TABLE I: Cross Country Regressions Of R\&D Intensity On The Percentage Of Natural Resource Rents To Gdp

\begin{tabular}{|c|c|c|c|c|c|}
\hline & (1) & $(2)$ & (3) & (4) & (5) \\
\hline CONSTANT & $\begin{array}{c}1.361 \\
(10.14) \\
*\end{array}$ & $\begin{array}{c}.8732 \\
(4.53) \\
*\end{array}$ & $\begin{array}{l}-.2700 \\
(-.763)\end{array}$ & $\begin{array}{c}-1.340 \\
(-2.28) \\
* *\end{array}$ & $\begin{array}{l}-.8707 \\
(-1.46)\end{array}$ \\
\hline RENTSTOGDP & $\begin{array}{c}-.0330 \\
(-3.46) \\
*\end{array}$ & $\begin{array}{c}-.0230 \\
(-3.30) \\
*\end{array}$ & $\begin{array}{c}-.0262 \\
(-3.02) \\
*\end{array}$ & $\begin{array}{c}.0224 \\
(-2.52) \\
* *\end{array}$ & $\begin{array}{c}-.0276 \\
(-3.14) \\
*\end{array}$ \\
\hline PCGDP & & $\begin{array}{c}.000018 \\
(3.41) \\
*\end{array}$ & $\begin{array}{c}.00018 \\
(3.61) \\
*\end{array}$ & $\begin{array}{c}.000012 \\
(1.66)\end{array}$ & $\begin{array}{c}.000020 \\
(2.56) \\
* *\end{array}$ \\
\hline GOVTTOGDP & & & $\begin{array}{c}.0646 \\
(3.66) \\
*\end{array}$ & $\begin{array}{c}.0708 \\
(3.69) \\
*\end{array}$ & $\begin{array}{c}.0560 \\
(2.88) \\
*\end{array}$ \\
\hline EASEOFCAP & & & & $\begin{array}{c}.4031 \\
(2.12) \\
* *\end{array}$ & $\begin{array}{c}.4100 \\
(2.24) \\
* *\end{array}$ \\
\hline TRADETOGDP & & & & & $\begin{array}{c}.0038 \\
(-2.48) \\
* *\end{array}$ \\
\hline RSQ & .142 & .265 & .404 & .516 & .560 \\
\hline $\mathrm{N}$ & 74 & 73 & 71 & 67 & 67 \\
\hline
\end{tabular}

The table is constructed in a rather typical fashion. The first column shows the potential explanatory variables that can enter the regression equations. This column is followed by five other columns. Each of these subsequent columns provides the results of a single regression run. The regression equations are numbered in the very first row. The very last row shows the 
size of the sample for each regression, and the second to last row provides the r-squared value for each equation. The body of the table supplies the estimated coefficients and the individual t-statistics for variables if and when they enter an equation. The top value is the estimated coefficient and the number in parenthesis under the estimated coefficient is the individualstatistic. Variables that are significant at the one percent level or better in an equation are marked with a single asterisk, while those that are significant at the five percent level or better are shown with two asterisks.

Table I consists of five equations. The first equation looks at the effect of natural resource rental income share on R\&D intensity on its own without adjusting for any of the control variables, while the remaining four equations, consider the effect of natural resource rental income share on R\&D intensity adjusting for one or more control variables.

The results lend support to the hypothesis that greater natural resource rental income is detrimental to country research and development. The coefficient on the percentage of rental income to GDP (RENTTOGDP) is negative and significant at the one percent level of significance or better in four of the five equations (equation (1), (2), (3), and (5)), and is negative and significant at the five percent level or better in the sole remaining equation (equation (5). When it is used in the first equation as the lone regressor to explain R\&D intensity, the percentage of rental income to GDP on its own explains over fourteen percent of the cross country variation in R\&D intensity, the percentage of R\&D to GDP, in a sample of eighty four countries. When used in combination with the four other explanatory variables (equation (5)), the estimated coefficient on rental income to GDP (RENTSTOGDP) indicates that an upward jump by one percentage point in rental income to GDP leads to a reduction in the percentage of R\&D to GDP by close to three hundredth of a percentage point.

All of the control variables also work fairly nicely. The estimated coefficient on per capita GDP (PCGDP) is positive, in the four equations that it appears (equations (2)-(5)), indicating, as theoretically expected, that higher levels of economic development improve R\&D intensity. Although per capita GDP is not significant in the fourth equation, it is significant at the one percent level or better in equations two and three, and at the five percent level or better in equation five.

The government size variable, the percentage of government expenditures to GDP (FGOVTTOGDP), is consistently strong. It is positive and significant at the one percent level of significance or better in each of the three equations in which it appears (Equations (3)-(5)).

In line with the research findings of others that financial availability is a positive driver of R\&D, in the two equations that it enters (equations (4) \& (5)), the financial availability variable used here, the ease of obtaining venture capital (EASEOFCAP), is positive and significant at the five percent level.

Lastly, and, again, consistent with the research of others, trade openness is found to have a negative effect on R\&D intensity. Looking at equation five, shows that the estimated coefficient on the percentage of trade to GDP (TRADETOGDP) is negative and significant at the five percent level of significance. Taken together, the percentage of natural resources rents to GDP when combined with all the other variables (equation (5)) explains fifty six percent of the cross country variation in R\&D intensity for sixty seven countries.

In sum, the empirical evidence strongly suggests that natural resource rental income matters for country R\&D Whether the percentage of natural resource rents to GDP is used alone (equation (1)), or when controlling for other explanatory variables (equations (2)-(5)), the 
percentage of rental income to GDP has a negative and statistically significant effect on R\&D intensity.

\section{CONCLUSION}

The empirical findings of this paper suggest that greater natural resource rental share has an adverse effect on research and development intensity. Reduced levels of R\&D have potential dire consequences for an economy. Lower levels of research and development are unfavorable for sustained long run economic growth and development. Economic development requires that growth becomes automatic or built-in to the economic system. This entails, among other things, a major structural shift toward high valued production such as manufacturing, and, more importantly, it requires the establishment and promotion of high levels of R\&D.

Societies that are blessed with scarce natural resources, such as oil, that generate natural resource rents, need to be particularly on guard. If they are not careful, the future trajectory that their society takes, economically, politically, and culturally, may not be promising. Rental income may be favored over other forms of income both as a source of income, and in terms of social status and prestige. The educational system may be geared to breeding gentlemen instead of engineers and scientists. The elites, who control the government, governmental policy, and the tone of society, assured of their rental incomes, may sit back on their laurels, and may, except perhaps for some lip service, have little real concern for economic development. And, even if the event that elites do become worried about economic development, the higher exchange rates resulting from the export of internationally scarce natural resources put industrial development of the domestic economy at an extreme disadvantage, making economic development more difficult.

\section{REFERENCES}

Becker, Bettina. 2013. "The Determinants of R\&D Investment: A Survey of the Empirical Research." Loughborough University Discussion Paper 2013-09, http://www.lboro.ac.uk/departments/sbe/RePEc/lbo/lbowps/Becker_DP.pdf, June 23, 2014.

Bebczuk, Ricardo N. 2002. "R\&D Expenditures and the role of Government around the World." Estudios de Economia, 29:1, pp. 109-121.

Falk, Martin. 2006. "What Drives Business R\&D Intensity across OECD Countries?" Applied Economics, 38, pp. 533-547, http://www2.druid.dk/conferences/viewpaper.php?id=2730\&cf=18, June 18, 2014.

Hillier, David, Julio Pindado, Valdoceu de Queiroz and Chabela de la Torre. 2011. The Impact of Country-Level Corporate Governance on Research and Development." Journal of International Business Studies, 42, pp. 76-98.

Kanwar, Sunil and Robert Evenson. 2003. "Does Intellectual Property Protection Spur Technological Change?" Oxford Economic Papers, 58:2, pp. 235-264.

Yang, Chih-Hai and Ying-Hui Chen. 2012. "R\&D, Productivity, and Exports: Plant-Level Evidence from Indonesia." Economic Modelling, 29:3, pp. 208-216.

Wang, Cong. 2013. "Can Institutions Explain Cross Country Differences in Innovative Activity?" Monash University Business and Economics Discussion Paper 35/13,

http://www.buseco.monash.edu.au/eco/research/papers/2013/3513institutionswang.pdf, June 17, 2014.

World Bank. 2014. World Development Indicators,

http://databank.worldbank.org/data/views/variableSelection/selectvariables.aspx?source=world-developmentindicators, May 20, 2014.

World Economic Forum. 2011. The Global Competitiveness Report 2010-2011.

http://www3.weforum.org/docs/WEF_GlobalCompetitivenessReport_2010-11.pdf, June 20, 2014. 